\title{
Using admission from the emergency room to improve predictions of resource use and length of stay for acute inpatient admissions in Ontario
}

\author{
M Perry ${ }^{*}$, M Alshurafa \\ From 26th Patient Classification Systems International (PCSI) Working Conference \\ Munich, Germany. 15-18 September 2010
}

\begin{abstract}
Introduction
The use of emergent status is believed to provide an easily auditable approach towards capturing patient acuity. Current case-mix methodologies in Ontario for the acute inpatient population make very limited use of the emergent status of patients (whether the patient was admitted from the emergency room). These patients tend to be longer stay, and current resource utilization indicators are poor predictors of patient-episode cost. The average patient who is admitted to an Ontario acute inpatient facility from an emergency room stays 3.5 days longer, costs $\$ 685$ more and is 4 times more likely to die in hospital than a patient who is not admitted from an emergency room at that facility (unadjusted for case mix).
\end{abstract}

\section{Methods}

This study will proceed based on retrospective analysis of observational data from Ontario public hospitals. Clinical and administrative data sources will include acute inpatient data (Discharge Abstract Database, DAD), ambulatory care data (National Ambulatory Care Reporting System, NACRS) and patient episode cost data from the Ontario Case Costing Initiative (OCCI). The data will be linked across settings using an encrypted unique identifier. Emergent status is a dichotomous variable. The study period is April 2007 to March 2009 (2 years).

Differences in length of stay (LOS) and episode cost for patients of different emergent status will be examined, as well as residual length of stay and cost based on estimates from the CMG+ grouping methodology

Ontario Ministry of Health and Long-Term Care, Toronto, Ontario, Canada developed by the Canadian Institute for Health Information. The independent variables will include case-mix classification, age, hospital status, hospital size and others.

\section{Results}

\section{Length of Stay}

Using a residual regression on two years of data, the emergent flag was found to be significant $(p<0.05)$ in 302 of the 553 case mix groups (CMG) in the CMG+ methodology, and very significant $(p<0.001)$ for 208 of the CMG. In the latter cases, the average estimated absolute residual was 2.13 days (median 1.9 days) while 39 CMG had a parameter estimate of 4 days or more. The emergent flag also shows a bias related to the identification of long stay outliers (LSO), with $4.46 \%$ of records with an emergent flag being identified as LSO, and only $1.83 \%$ of non-emergent records being flagged as LSO.

\section{Cost}

A residual regression on cost shows that the emergent variable is significant in 105 CMG $(p<0.05)$ and very significant $(\mathrm{p}<0.001)$ for $28 \mathrm{CMG}$ for the two years of analysis. In contrast to expectations, for the $28 \mathrm{CMG}$ with a p-value less than $0.001,22$ of the CMG are resulting in over-predictions of cost, while 188 of the 208 that are significant for LOS $(\mathrm{p}<0.001)$ are underpredicting the length of stay.

\section{Conclusions}

Acute inpatient facilities in Ontario have significantly different rates of admission from the emergency room, with reported facility rates ranging from $0-100 \%$ of admitted acute inpatients coming from the ER. The 
inclusion of emergent status into current case-mix methodologies would significantly improve the accuracy of length of stay and cost, as well as predictions of survival rates that are used to compare the efficiency of facilities.

Since emergent status is easily auditable, and has an apparent impact above and beyond the comorbidity system in use in Canada, it could be used as a proxy for patient severity to increase the predictive power of casemix methodologies in countries or jurisdictions where reliable comorbidity reporting is unavailable.

The implications of these results are that emergent status should be considered for future case-mix methodologies where length of stay and cost estimation is of paramount importance.

This continues to be a work in progress.

Published: 6 October 2010

doi:10.1186/1472-6963-10-S2-A21

Cite this article as: Perry and Alshurafa: Using admission from the emergency room to improve predictions of resource use and length of stay for acute inpatient admissions in Ontario. BMC Health Services Research 2010 10(Suppl 2):A21.
Submit your next manuscript to BioMed Central and take full advantage of:

- Convenient online submission

- Thorough peer review

- No space constraints or color figure charges

- Immediate publication on acceptance

- Inclusion in PubMed, CAS, Scopus and Google Scholar

- Research which is freely available for redistribution

Submit your manuscript at www.biomedcentral.com/submit 